\title{
Improving Senior Secondary Students' Retention in Electrolysis Using Collaborative Concept Mapping Instructional Strategy (CCMIS)
}

\section{Oluwatosin Victor Ajayi \& Terfa Michael Angura}

\author{
Department of Curriculum and Teaching, Benue State University, Makurdi, Nigeria
}

E-mail: drvictorajayi@gmail.com

\begin{abstract}
In this study, improving senior secondary students' retention in electrolysis using Collaborative Concept Mapping Instructional Strategy (CCMIS) was examined. A sample of 189 students from six selected secondary schools out of a population of 5,114 Senior Secondary I students from Ardo-Kola Local Government Area of Taraba State, Nigeria was used for the study. Non-equivalent quasi-experimental research design was adopted. The instrument used for data collection was Electrolysis Retention Test (ERT) with the reliability value of 0.78 using Kuder-Richardson. Two research questions and three null hypotheses guided the study. Mean and Standard Deviation scores were used to answer the research questions while Analysis of Covariance (ANCOVA) was used to test the null hypotheses. The study revealed that there is significant difference in the mean retention scores between students taught electrolysis using CCMIS and discussion method in favour of CCMIS; $[F(1,97)=6.300, P<0.050]$. No significant difference was found in the mean retention scores between male and female students taught electrolysis using CCMIS; $[F(1,97)=6.300, P>0.050]$. It also found no significant interaction effect between methods and gender on the mean retention scores of students in electrolysis; $[F(1,197)=.318, P>0.050]$. It was recommended among others that CCMIS should be adopted while teaching electrolysis since it has been proved to be a viable option in enhancing students' retention capacity regardless of their gender.
\end{abstract}

Key words: Collaborative Concept Mapping Instructional Strategy (CCMIS), retention, electrolysis.

\section{INTRODUCTION}

Science education has been proved to be an indispensable factor in the economic and technological development of any nation; and for Nigeria, it has a more critical role to play. Chemistry is one of the core subjects in science education which deals with the scientific study of the composition, structure, properties, and reactions of matter in different forms. Its study involves exploration of relationship between theory and experiment. Electrolysis which is the main focus of this study is the Chemical decomposition produced by passing an electric current through a liquid or solution containing ions or is a process by which electrical energy is used to produce a chemical change and is commercially important as a stage in the separation of elements from naturally occurring sources such as ores using an electrolytic cell and has also been found very useful in modern society. It is utilized in mining industries, chlor-alkali industry for making chlorine and caustic which are valuable for modern society due to their myriad uses and also the electrolysis of water is used in the production of hydrogen for fuel, or the generation of electricity using fuel cells. The importance of chemistry in national development cannot be over emphasized. According to Asiyai (2005), Chemistry has helped in the development of modern technology through the application of its principles in modern invention. Despite the important of chemistry, the problem of students' poor retention capacity in chemistry is undoubtedly worrisome and has been a major concern to the educationalist.

Several studies such as studies by Achor and Imoko et al (2009), Kurumeh and Onah, et al (2012), Ajayi and Ogbeba (2017) have revealed unimpressive students' retention rate at the senior secondary school level in Nigeria. Several studies have attributed the observed students' poor retention capacity to the use of inappropriate and 
ineffective teaching methods such as lecture and discussion method. In the same vein, Paden and Dereskiwsky (2007) revealed in their study that low retention rate of students particularly among sexes is as a result of instructional modality adopted by teachers. In this regard, Inappropriate teaching methods use by chemistry teachers invariably translates to students' inability to retain and put into practice what is learnt in reality has become a hydraheaded problem. In most cases what is taught in classroom cannot be transferred to real life situation by students. This problem, if not nipped in the bud, will have adverse consequences on the students and the society at large, given the importance of chemistry in Nigeria's scientific and technological development. There is therefore, the need to explore innovative methods for effective teaching of chemistry specifically electrolysis so as to enhance students' retention in the subject.

One of such innovative methods is the Collaborative Concept Mapping Instructional Strategy (CCMIS). CCMIS is a hybrid teaching/learning strategy involving an interaction between two or more individuals during concept mapping to create a shared understanding of a previously possessed or could have come to on their own (Keraro \& Wachanga, 2011). CCMIS or concept mapping in a group setting is a process where two or more individuals are engaged in coordinated and sustained efforts in the creation of one or more concept maps in order to learn and construct knowledge. Collaborative concept mapping strategy connotes sharing ideas. Consequently, concept mapping strategy becomes collaborative when instead of an individual drawing the map, a group of students come together to brainstorm, share ideas, generate a pool of concepts/facts, which when put together, they eventually come out with a map that represents the thought of the group.

It is one thing to be taught chemistry specifically electrolysis via appropriate strategy; it is another thing to remember it after some reasonable period of time must have elapsed that is retention. Retention as defined by Hornby (2001) is the ability to remember things. For the purpose of this study, retention is defined as the ability to keep or retain the knowledge of electrolysis learnt and to be able to recall it when required. Retention in chemistry is not acquired by mere rote-memorization but through appropriate teaching method. In this regard, the researcher sees the need to find out if CCMIS could improve both male and female students' retention in electrolysis. The term gender is often used to indicate the distinction between human beings based on masculinity and femininity in relation to their expected roles in the society.

Gender is ascribed to attitude which differentiates feminine from masculine in retention due to gender inequality which has caused a lot of concern to educationalists. In this regard, the differences between boys and girls in relation to students' retention in chemistry have received a lot of attention in recent years. Some studies indicate that boys have higher retention than girls (Esan, 2009), either no difference (Ajayi, 2017) or girls have higher retention than boys (Bala, 2011; Ajibola, 2014) have been demonstrated. Studies on gender differences in chemistry retention continue to yield inconsistence results and it has usually been attributed to unequal exposure of boys and girls to learning instructions relevant to chemistry learning. In this regard, the study examined improving senior secondary students' retention in electrolysis using Collaborative Concept Mapping Instructional Strategy (CCMIS) in Ardo-Kola Local Government Area of Taraba State as a study area. Specifically, the purpose of the study was to;

1. Determined the effect of CCMIS on students' retention in electrolysis

2. Determined the difference in effect of CCMIS between male and female students' retention in electrolysis.

3. Ascertained the interaction effect between methods and gender on students' retention in electrolysis

\section{$1.1 \quad$ Research Questions}

The following research questions guided this study:

1. What is the difference in the mean retention scores between students taught electrolysis using CCMIS and those taught using discussion method?

2. What is the interaction effect between methods and gender on students mean retention scores in electrolysis?

\section{$1.2 \quad$ Hypotheses}

The following null hypotheses were tested:

1. There is no significant difference in the mean retention scores between students taught electrolysis using CCMIS and those taught using discussion method

2. There is no significant difference in the mean retention scores between male and female students taught electrolysis using CCMIS. 
3. There is no significant interaction effect between methods and gender on the mean retention scores of students in electrolysis.

\section{RESEARCH DESIGN AND PROCEDURE}

The study used quasi experimental design. Specifically, it was non-equivalent pre-test, post and retention test design. The design was considered appropriate because intact classes were used. The study area was ArdoKola Local Government Area of Taraba State, Nigeria. The population of the study comprised all the 4,286 SSII students in the 32 government approved secondary schools. 100 male and 89 female students were randomly sampled from 6 coeducational schools. One intact class from each of the six sampled schools was selected using simple random sampling. They were assigned randomly to experimental and control groups. The experimental and control groups, each comprised three intact classes totaling six intact classes. The experimental group was taught electrolysis using Collaborative Concept Mapping Instructional Strategy (CCMIS) in line with lessons procedure prepared by the researcher while the control group was taught electrolysis using the discussion lesson notes.

An instrument known as Electrolysis Retention Test (ERT) developed by the researchers and validated by four experts from science education/measurement and evaluation was used to collect the data. ERT was administered on students as pre, post and retention test after successive reshuffling so as to measure students' retention. ERT contained two sections. Section "A" contained demographic information of the respondents, while section "B" contained a 30 multiple choice items. Each of the items contains options A-D which respondents are expected to choose the correct option. The reliability coefficient of ERT using Kuder Richardson (KR-21) was 0.78 which shows a high level of internal consistency of the instrument and hence it was considered reliable enough to be used for data collection in this study.

Before the commencement of the treatment, ERT was administered by the chemistry teachers (research assistants) on the students as pre-test. However after the actual teaching which lasted for six weeks of fourteen periods, ERT was administered as post-test though reshuffled. The pre-test scores constituted the covariate of the post-test scores. The researchers allowed a gap of another period of four weeks in order to find out if the knowledge gained is retained. The instrument ERT was then reshuffled and administered as retention test to measure the students on retention in each of the group. The ERT was collected and used for analysis. The research questions were answered using Mean and Standard Deviation scores while the hypotheses were tested at 0.05 level of significance using Analysis of Covariance.

\section{$3 \quad$ RESULTS AND TABLES}

\section{Research Question One}

What is the difference in the mean retention scores between students taught electrolysis using Collaborative Concept Mapping Strategy (CCMIS) and those taught using discussion method? The answer to research question one is contained in Table 1.

\begin{tabular}{lcccccc}
\multicolumn{7}{l}{ Table 1: Mean Retention and Standard Deviation Scores of Students taught Electrolysis using } \\
CCMIS and Discussion Method
\end{tabular}

Table 1 revealed that, the mean difference between the two groups was 9.43 in favour of the Collaborative Concept Mapping Instructional Strategy (CCMIS) group. It implies that the CCMIS group had higher retention capacity than the discussion method group. 


\section{Research Question Two}

What is the interaction effect between methods and gender on students mean retention scores in electrolysis? The answer to research question two is presented in Table 2 .

\begin{tabular}{|c|c|c|c|c|}
\hline \multirow{2}{*}{$\begin{array}{l}\text { Gender } \\
\text { Male }\end{array}$} & \multirow{2}{*}{$\begin{array}{l}\text { Method } \\
\text { CCMIS }\end{array}$} & \multirow{2}{*}{$\begin{array}{l}\mathrm{N} \\
49\end{array}$} & \multicolumn{2}{|c|}{ RETENTION-TEST } \\
\hline & & & 28.89 & 4.97 \\
\hline & Discussion & 51 & 18.77 & 3.74 \\
\hline \multirow[t]{2}{*}{ Female } & CCMIS & 44 & 28.81 & 4.93 \\
\hline & Discussion & 45 & 17.24 & 3.12 \\
\hline
\end{tabular}

The results in Table 2 revealed that, the mean retention scores of male students taught electrolysis using Collaborative Concept Mapping Instructional Strategy (CCMIS) and discussion method are 28.89 and 18.77 respectively while the mean retention scores of female students taught electrolysis using CCMIS and discussion method are 28.81 and 17.24 respectively. This shows that CCMIS is superior to discussion method in enhancing both male and female students' retention in electrolysis.

\section{Hypothesis One}

There is no significant difference in the mean retention scores between students taught electrolysis using CCMIS and those taught using discussion method. The answer to hypothesis one is presented in Table 3.

Table 3: ANCOVA Test for Mean Retention Scores of Students taught Electrolysis using CCMIS and Discussion Method

\begin{tabular}{lccrrr}
\hline Source & $\begin{array}{l}\text { Type III sum } \\
\text { of square }\end{array}$ & & Mean Square & $F$ & Sig \\
\hline Corrected model & $5010.009 a$ & 2 & 701.717 & 319.094 & .000 \\
Intercept & 3120.112 & 1 & 3120.112 & 198.507 & .000 \\
Pre-test & 310.008 & 1 & 310.008 & 107.070 & .000 \\
Method & 103.009 & 1 & 103.009 & 12.972 & .000 \\
Error & 728.144 & 186 & 34.021 & & \\
Total & $\mathbf{8 8 0 9 3 . 0 0 9}$ & $\mathbf{1 8 9}$ & & & \\
Corrected Total & $\mathbf{7 9 9 . 9 0 0}$ & $\mathbf{1 8 8}$ & & & \\
\hline
\end{tabular}

a. $\quad$ R squared $=.401$ (Adjusted R Squared $=.425$ )

ANCOVA Test results in Table 3 reveal that there is a significant difference between the mean retention of students taught electrolysis using CCMIS and discussion method in favour of CCMIS; $[F(1,188)=12.972, P<0.050]$. The null hypothesis is therefore rejected. This implies that CCMIS significantly enhanced students' retention in electrolysis when compared with discussion method.

\section{Hypothesis Two}

There is no significant difference in the mean retention scores between male and female students taught electrolysis using CCMIS. The answer to hypothesis two is presented in Table 4. 
Table 4: ANCOVA Test for Mean Retention Scores of Male and Female Students taught Electrolysis using CCMIS

\begin{tabular}{lcrrrr}
\hline Source & $\begin{array}{l}\text { Type III sum } \\
\text { of square }\end{array}$ & & Mean Square & $F$ & Sig \\
\hline Corrected model & $4949.190 \mathrm{a}$ & 2 & 529.900 & 98.009 & .000 \\
Intercept & 2929.001 & 1 & 2929.001 & 73.005 & .000 \\
Pre-test & 321.021 & 1 & 321.021 & 47.202 & .000 \\
Gender & 2.338 & 1 & 2.338 & .222 & .109 \\
Error & 541.111 & 90 & 35.999 & & \\
Total & $\mathbf{4 3 9 0 9 9 . 9 0 9}$ & $\mathbf{9 3}$ & & & \\
Corrected Total & $\mathbf{2 8 9 9 . 0 0 0}$ & $\mathbf{9 2}$ & & & \\
\hline
\end{tabular}

a. $\quad$ R squared $=.409$ (Adjusted R Squared $=.487$ )

ANCOVA Test results in Table 4 reveal that there is no significant difference between the mean retention of male and female students taught electrolysis using CCMIS $[F(1,92)=.222, P>0.050]$. The null hypothesis is therefore not rejected. This implies that CCMIS enhanced both male and female students' retention in electrolysis.

\section{Hypothesis Three}

There is no significant interaction effect between methods and gender on the mean retention scores of students in electrolysis. The answer to hypothesis three is presented in Table 5

Table 5: ANCOVA Tests for Interaction Effect between Methods and Gender on Students' Retention in Electrolysis

\begin{tabular}{lccccc}
\hline Source & $\begin{array}{c}\text { Type III sum } \\
\text { of square }\end{array}$ & & Mean Square & $F$ & Sig \\
\hline Corrected model & $3256.100 \mathrm{a}$ & 2 & 239.007 & 83.890 & .000 \\
Intercept & 3700.009 & 1 & 3700.009 & 43.975 & .000 \\
Pre-test & 288.091 & 1 & 288.091 & 90.907 & .000 \\
Methods*Gender & .101 & 1 & .101 & .702 & .477 \\
Error & 309.800 & 186 & 13.009 & & \\
Total & $\mathbf{7 3 9 7 0 0 0 . 0 0 0}$ & $\mathbf{1 8 9}$ & & & \\
Corrected Total & $\mathbf{3 1 0 0 . 0 0 1}$ & $\mathbf{1 8 8}$ & & & \\
\hline
\end{tabular}

a. $\quad$ R squared $=.129$ (Adjusted R Squared $=.101$ )

ANCOVA results in Table 5 revealed that there is no significant interaction effect between methods and gender on the mean retention scores of students in electrolysis; $[F(1,188)=.702, P>0.050]$. The null hypothesis is therefore not rejected. This implies that there is no need for separation of instructional method for male and female students since CCMIS can successfully be used to enhance the retention of the two groups.

\section{DISCUSSION OF FINDINGS}

In this study, improving students' retention in electrolysis using Collaborative Concept Mapping Instructional Strategy (CCMIS) was examined. The findings of this study revealed that students taught electrolysis using CCMIS had higher retention rate than their counterparts taught using discussion method. This finding agrees with Ann (2011) who found that Students have higher retention capacity when exposed to CCMIS than their counterparts that were exposed to traditional method in Basic Science and Technology. The likely explanation for this outcome may be connected to the fact that the CCMIS helped the learner to possess a meaningful in-depth knowledge of the content area when compared to the discussion method.

The findings of this study also revealed that there is no statistical significant difference between male and female students' retention using CCMIS. In the same vein, the finding of this study also revealed that there is no significant interaction effect between methods and gender on mean retention scores of students in electrolysis. This implies that, CCMIS is superior to the discussion method irrespective of gender in fostering students' retention. In this case, there is no need for separation of instructional method for male and female students since CCMIS can be used successfully for the two groups. 


\section{CONCLUSION}

It is proved from the findings of this study that the use of Collaborative Concept Mapping Instructional Strategy (CCMIS) is more effective in facilitating and improving male and female students' retention in electrolysis than discussion method. By implication, this affirmed that students retention in electrolysis depend on the method of instruction. Thus, CCMIS is significantly a very useful instructional strategy for increased meaningful learning and higher retention of students regardless of their gender.

\section{RECOMMENDATIONS}

1. Collaborative Concept Mapping Instructional Strategy (CCMIS) should be adopted by senior secondary school chemistry teachers for teaching electrolysis, since it has been proved to be a viable option in enhancing students' retention capacity in electrolysis.

2. CCMIS is not gender sensitive; therefore, both male and female students should be involved in electrolysis to enhance their retention in chemistry concept specifically electrolysis.

3. Ministry of Education and professional bodies such as Association of Professional Educators (APE), Teacher Registration Council of Nigeria (TRCN) and Science Teachers Association of Nigeria (STAN) should organised conferences and workshops where the CCMIS will be exposed to teachers for better application and to meet up with the challenges and demands of the new curriculum.

\section{REFERENCES}

Achor, E.E., Imoko, B.I. \& Uloko, E.S. (2009). Effect of ethnomathematics teaching approach on senior secondary students' achievement and retention in locus. Educational Research and Review, 4(8), 385-390.

Ajayi, O.V. \& Ogbeba, J. (2017). Effect of gender on senior secondary chemistry students' achievement in stoichiometry using hands-on activities. American Journal of Educational Research, 5(8), 839- 842.

Ajibola, A. (2014.) Effects of two methods of teaching on students' retention in basic science and technology. Journal of Education and practice, 3(3), 12-18.

Bala, B. (2011). Quality and students achievement. A review of state policy evidence. Educational Policy Analysis, 8(1), 39-43.

Esan, J.N. (2009). Achievement, retention and gender in Science Education. Journal of Research in Educational Review, 2(5), 43-48.

Keraro, F.N. \& Wachanga, S.W. (2011). Effect of cooperative concept mapping teaching approach on secondary school students' motivation in Biology in Gucha District, Kenya. International Journal of Science and Mathematics Education, 5(1), 111-124.

Paden, R.R. \& Dereskiwsky, M.I. (2007). A comparison of students' achievement and retention in an introductory mathematics course. A paper presented to the teaching, colleges and community (TCC). Worldwide conference, April, 17-19.

Kurumeh, M.S., Onah, F.O., \& Mohammed, A.S. (2012). Improving students' retention in junior secondary school statistics using ethno-mathematics teaching approach in Obi and Oju Local Government Area of Benue State, Nigeria. Greener Journal of Educational Research, 2(3), 54-62. 